\title{
Can the 6-minute walking test evaluate all patients with respiratory disease?
}

Marta R. Q. Pimentel, ${ }^{1}$ Yves Raphael, ${ }^{1}$ Luciane V. B. Nascimento, ${ }^{1}$ Rogério Rufino, ${ }^{2}$ Adalgisa Maiworm, ${ }^{3}$ Kenia Maynard da Silva, ${ }^{3}$ Cláudia Henrique da Costa ${ }^{3 *}$

\begin{abstract}
The 6-minute walking test (6MWT) is a submaximal test used as a clinical indicator of functional capacity in patients with pulmonary disease. However, is has not been defined whether the parameters obtained in the 6MWT are similar in two groups of interstitial lung diseases (ILD), systemic sclerosis (SSc) and idiopathic pulmonary fibrosis (IPF), and what are the differences when compared to patients with chronic obstructive pulmonary disease (COPD). This is a comparative cross-sectional study of 6MWT data, with the inclusion of 32 patients with SSc, 32 with IPF and 50 with COPD. All patients underwent the $6 \mathrm{MWT}$ and a respiratory function test. Patients with ILD did not present significant differences when compared with each other. However, when compared to patients with COPD, the ILD group showed greater distance walked $(\mathrm{ILD}=404.6 \pm 1.09 \mathrm{~m}, \mathrm{COPD}=352.4 \pm 10.80 \mathrm{~m} ; \mathrm{p}=0.0033)$ and predicted percentage above $100 \%$ (ILD $=113.5 \pm 3.72 \%$, COPD $=84.36 \pm 4.81 \%$; $\mathrm{p}<0.0001)$. Both groups showed a drop in blood oxygen saturation $\left(\mathrm{SaO}_{2}\right)$ at the end of the test, but the difference between the measured values before and after the 6MWT was more significant in the ILD group (ILD $=10.33 \pm$ $01.09 \%, \mathrm{COPD}=4.60 \pm 12.37 \%$; $\mathrm{p}<0.0001$ ). The data suggest that, differently from COPD patients, the main parameter to be evaluated during the 6MWT in the ILD group could be the drop in saturation and not the distance walked.
\end{abstract}

Keywords: COPD; Lung diseases, Interstitial; Respiratory Function Tests; Walk Test; Walking.

\section{Resumo}

O teste de caminhada de 6 minutos avalia igualmente todos os pacientes com doença respiratória?

O teste de caminhada de 6 minutos (TC6) é uma avaliação submáxima utilizada como indicadora clínica de capacidade funcional em pacientes com doença pulmonar. Noentanto, não se sabe se os parâmetros obtidos no TC6 são semelhantes em dois grupos de doenças intersticiais pulmonares (DIP), esclerose sistêmica (ES) e fibrose pulmonar idiopática (FPI), e quais são as diferenças quando comparados com pacientes com doença pulmonar obstrutiva crônica (DPOC). Esteé um estudo transversal comparativo dos dados do TC6 com inclusão de 32 pacientes com ES, 32 com FPI e 50 com DPOC. Todos os pacientes foram submetidos ao TC6 e a um teste de função respiratória.Pacientes com DIP não apresentaram diferenças significativas quando comparados entre si. Entretanto, quando comparados aos pacientes com DPOC, ogrupo com DIP apresentou maior distância
1. Respiratory Department, Rio de Janeiro State University, Rio de Janeiro, Brazil.

2. Pneumology Department, University Hospital of Rio de Janeiro State University, Rio de Janeiro State University, Rio de Janeiro, Brazil.

3. Respiratory Department, University Hospital of Rio de Janeiro State University, Rio de Janeiro State University, Rio de Janeiro, Brazil.

*Correspondence address:

Av. Vinte e Oito de Setembro, 77

Rio de Janeiro, Brazil.

ZIP 20551-030

E-mail: ccosta.uerj@gmail.com

BJHBS, Rio de Janeiro, 2019;18(2):136-143

Received on 07/16/2019. Approved on 09/05/2019.

percorrida $(\mathrm{DIP}=404,6 \pm 1,09 \mathrm{~m}, \mathrm{DPOC}=352,4 \pm 10,80 \mathrm{~m} ; \mathrm{p}=$ 0,0033 ) e percentual previsto acima de $100 \%$ (DIP $=113,5 \pm 3,72 \%$, $\mathrm{DPOC}=84,36 \pm 4,81 \%$, $\mathrm{p}<0,0001$ ). Ambos os grupos mostraram uma queda na saturação de oxigênio no sangue $\left(\mathrm{SaO}_{2}\right)$ ao final do teste, mas a diferença entre os valores medidos antes e após o TC6 foi mais significativa no grupo com DIP (DIP $=10,33 \pm$ $01,09 \%, \mathrm{DPOC}=4,60 \pm 12,37 \%, \mathrm{p}<0,0001)$. Os dados sugerem que, diferentemente dos pacientes com DPOC, o principal parâmetro a ser avaliado durante o TC6 no grupo com DIP poderia ser a queda na saturação e não a distância percorrida.

Descritores: DPOC; Doenças pulmonares intersticiais; Testes de Função Respiratória; Teste de caminhada.

\section{Resumen}

¿La prueba de caminata de 6 minutos evalúa a todos los pacientes con enfermedad respiratoria por igual?

La prueba de caminata de 6 minutos (PC6) es una prueba submáxima utilizada como un indicador clínico de la capacidad funcional en pacientes con enfermedad pulmonar. Sin embargo, no se definió si los parámetros obtenidos en la PC6 son similares en dos grupos de enfermedades pulmonares intersticiales (EPI), esclerosis sistémica (ES) y fibrosis pulmonar idiopática (FPI), y cuáles son diferencias en comparación con pacientes 
con enfermedad pulmonar obstructiva crónica (EPOC). Este es un estudio transversal comparativo de los datos de PC6 con inclusión de 32 pacientes con ES, 32 con FPI y 50 con EPOC. Todos los pacientes fueron sometidos a PC6 y una prueba de función respiratoria. Los pacientes con ILD no presentaron diferencias significativas cuando se compararon entre sí. Sin embargo, en comparación con los pacientes con EPOC, el grupo de EPI mostró una mayor distancia recorrida $(\mathrm{EPI}=404.6 \pm 1.09 \mathrm{~m}, \mathrm{COPD}=$ $352.4 \pm 10.80 \mathrm{~m} ; \mathrm{p}=0.0033)$ y porcentaje predicho por encima del 100\% (EPI $=113.5 \pm 3.72 \%$, EPOC $=84,36 \pm 4,81 \%$; $<<0,0001$ ). Ambos grupos mostraron una caída en la saturación de oxígeno

\section{Introduction}

Systemic sclerosis (SSc) and idiopathic pulmonary fibrosis (IPF) are among the most prevalent interstitial lung diseases (ILD). SSc is a chronic disease of unknown aetiology, characterized by vascular changes and progressive fibrosis of the skin and organs involved. ${ }^{1}$ Pulmonary involvement is more frequent in SSC than in other collagen vascular diseases, representing a significant cause of morbidity and mortality.,3 IPF is defined as a specific form of chronic fibrosing interstitial pneumonia of unknown aetiology that occurs primarily in older adults, is limited to the lungs and is associated with the usual interstitial pneumonia (UIP) histological pattern. ${ }^{4}$ The disease is more common in men $(75 \%)$ and those with a history of smoking. ${ }^{5}$

Obstructive diseases are characterized by increased resistance to airflow, and include asthma and chronic obstructive pulmonary disease (COPD). The latter is characterized by chronic inflammation and airway remodelling, inflammation and destruction of the lung parenchyma, resulting in the obstruction of expiratory airflow and lung hyperinflation, with loss of elasticity and gas exchange disorder. ${ }^{6}$ The airflow limitation is due to the combination of reduced lung elastic recoil and increased airway resistance, causing dynamic lung hyperinflation, especially during exercise. ${ }^{?}$

The 6-minute walking test (6MWT) is considered to be a submaximal test, used as a clinical indicator of functional capacity in patients with heart and lung disease, and is an objective method used to measure the ability to perform activities of daily life. ${ }^{8}$ The main advantages of the 6MWT are its simplicity and minimal technological requirements, making it a cheap and widely applicable test. ${ }^{9}$ This test provides information regarding functional capacity, responsiveness to therapy and prognosis for a variety of cardiopulmonary diseases, and its use in COPD management is widely described in the literature. en sangre $\left(\mathrm{SaO}_{2}\right)$ al final de la prueba, pero la diferencia entre los valores medidos antes y después de la PC6 fue más significativa en el grupo EPI (EPI = $10.33 \pm 01.09 \%$, EPOC $=4.60 \pm 12,37 \%$; $p$ $<0,0001$ ). Los datos sugieren que, a diferencia de los pacientes con EPOC, el parámetro principal que se evaluará durante la PC6 en el grupo EPI podría ser la caída de la saturación y no la distancia recorrida.

Palabras clave: EPOC; Enfermedades pulmonares, intersticiales; Pruebas de función respiratoria; Prueba de caminata.

Thus, the aim of this study is to evaluate whether the parameters obtained in the 6MWT are similar in two groups of ILD (SSc and IPF) and to compare their results with those obtained from COPD patients.

\section{Methods}

\section{Study design}

A cross-sectional study was carried out that compared performances on the 6MWT by patients with ILD and COPD from September 2014 to October 2016. This study was approved by the Ethics Research Committee under protocol number 20569913.2.000.5259, and all subjects were informed about the proposed procedures and signed a free and informed consent before participating in the study.

A random selection of SSc patients with ILD was made, according to the procedures of the American College of Rheumatology..$^{10}$ The diagnosis of IPF was made following American Thoracic Society (ATS) criteria. ${ }^{11}$ COPD patients were classified according to the Global Initiative for Chronic Obstructive Lung Disease (GOLD). ${ }^{12}$ All patients were being followed at an outpatient clinic.

Patients with uncontrolled comorbidities (systemic hypertension, $\mathrm{PAH}$, cardiac arrhythmias, stroke or acute myocardial infarction during the previous three months), significant joint involvement or the use of prosthetic legs that compromised ambulation and severe hypoxaemia (initial $\mathrm{SaO}_{2}$ lower than 90\%) were excluded from the study. Patients with concomitant respiratory diseases, such as asthma or COPD, were excluded from the ILD groups. In the SSc group, individuals with mixed or overlapped collagen vascular disease were also excluded. In the COPD group, only ex-smokers with a smoking history of greater 


\section{Original article}

than 20 pack-years were included. Active smokers, patients with exacerbation history in the previous eight weeks, and with comorbidities, such as asthma and tuberculosis after-effects, were excluded.

\section{Procedures}

Patients underwent anamnesis and received guidance on clothing, food and the use of oxygen therapy before the 6MWT. In accordance with the standards of the ATS, the walk test was performed in the morning, in order to respect the principles of chronobiology, in an environment with controlled temperature around $24^{\circ} \mathrm{C}$, in a 40 -metre-long corridor with markings at every metre. ${ }^{13}$ Patients were instructed to walk as fast as possible, without running, for 6 minutes. They were allowed to stop the test if they had symptoms such as dyspnoea, chest pain, dizziness, excessive coughing or discomfort. They were informed about the remaining time at every minute with encouraging phrases like: 'you're doing well' and 'keep up the good work'. The 6MWT was performed three times, with a half-hour break between each test for recovery. Before and after each attempt, the heart rate, blood pressure, respiratory rate and $\mathrm{SaO}_{2}$ were measured and the Modified Borg

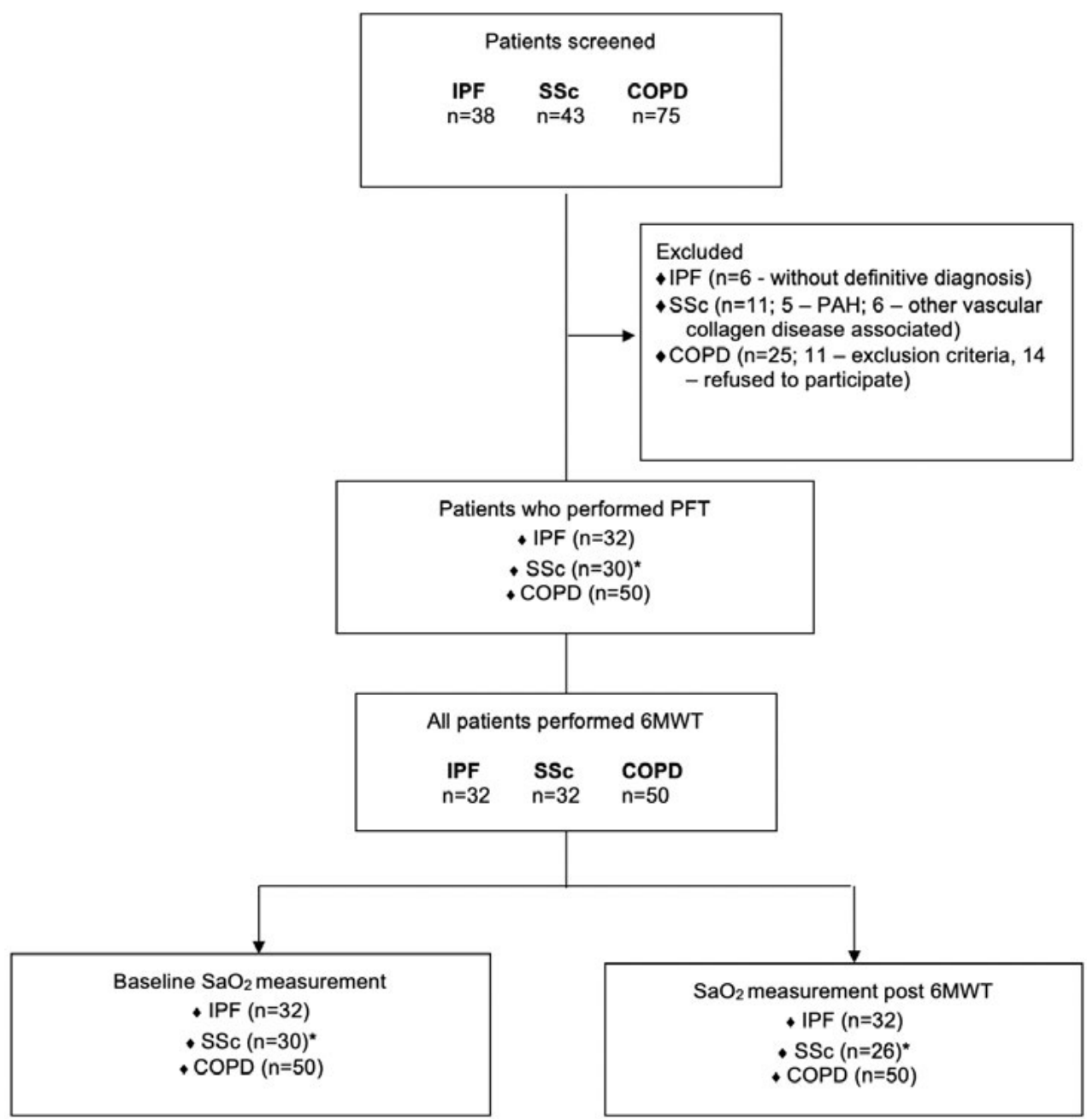

Figure 1. Flowchart

Legend: IPF: Idiopathic pulmonary fibrosis; SSc: systemic sclerosis; COPD: chronic obstructive pulmonary disease; PFT: pulmonary function test; SaO2: oxygen saturation; $\left({ }^{*}\right)$ PFT were nor performed in 2 patients with SSc due to technical problems and $\mathrm{SaO}_{2}$ could not be assessed in 2 patients before and in 6 at the end of GMWT due to Raynaud phenomenon. 
Scale of Perceived Exertion was applied. ${ }^{14}$ Only three patients with IPF were using supplementary oxygen and they were instructed to perform the examination with their routine supplementation. Patients with ILD underwent a pulmonary function test that included spirometry, body plethysmography and measurement of carbon monoxide diffusion (DLco), which was corrected for haemoglobin. Patients with COPD performed spirometry with a bronchodilator test on the same day as the 6MWT. All tests were performed on Collins Plus Pulmonary Function Testing Systems (Warren E. Collins, Inc, Braintree, MA, USA). Since COPD patients with cor pulmonale or supplementary oxygen were not included in the study, echocardiograms were not performed to rule out pulmonary hypertension in this patient population.

Patients with ILD underwent a chest computerized tomography (CT) scan to evaluate the interstitial pattern and an echocardiogram to rule out pulmonary hypertension that could have altered the results of the 6MWT.

\section{Statistical analysis}

Statistical analysis was performed using the GraphPad Prism 6.0 program, using Student's unpaired t-test and Pearson's correlation test to compare two groups. Comparison of three groups was performed using an ANOVA test. The data were presented as mean and standard deviation. A result was considered statistically significant when $\mathrm{p}<0.05$.

The calculation of the sample size was performed by comparing the means of the two ILD (SSc and IPF) using an unpaired t-test, with an alpha significance level of $5 \%$ and power of $95 \%$, and covering 45 individuals.Later, due to the similarities in the behavior of ILD patients, they were grouped into a single group, which was compared with COPD patients. The sample calculation with the same level of significance and power made necessary the inclusion of 45 patients in each group (restrictive and obstructive one).

\section{Results}

After checking the inclusion and exclusion criteria, we selected for this study 32 patients with SSc and interstitial lung involvement (28 women, 4 men), 32 patients with IPF (13 women, 19 men) and 50 patients with COPD (28 women, 22 men). The demographic and functional parameters are shown in Table 1.

Table 1. Demographic and functional data of patients with scleroderma, idiopathic pulmonary fibrosis and chronic obstructive pulmonary disease

\begin{tabular}{|c|c|c|c|c|}
\hline & SSc & IPF & COPD & \multirow{2}{*}{$\mathrm{p}$-value } \\
\hline & $\mathrm{n}=32$ & $\mathrm{n}=32$ & $n=50$ & \\
\hline Age (years) & $55.38 \pm 11.54$ & $67.59 \pm 8.89$ & $67.40 \pm 9.947$ & $<0.001$ \\
\hline Gender & 28 women; 4 men & 13 women; 19 men & 28 women; 22 men & \\
\hline Time of diagnosis* (years) & $6.39 \pm 6.99$ & $2.50 \pm 2.15$ & $\ldots$ & 0.0043 \\
\hline $\begin{array}{l}\text { Onset of symptoms* } \\
\text { (years) }\end{array}$ & $5.85 \pm 4.74$ & $3.69 \pm 3.09$ & $\underline{-}$ & 0.014 \\
\hline Smoking history & $n=9$ & $n=24$ & $\mathrm{n}=50 * *$ & \\
\hline FVC (\%) & $63.46 \pm 20.07 * * *$ & $66.07 \pm 20.44$ & $67.31 \pm 13.66$ & 0.016 \\
\hline FEV1 (\%) & $62.20 \pm 21.31^{* * *}$ & $73.22 \pm 21.79$ & $39.36 \pm 13.14$ & $<0.001$ \\
\hline Supplementary oxygen**** & 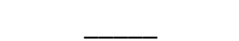 & $\mathrm{n}=3$ & $\underline{-}$ & \\
\hline
\end{tabular}

Legend: SSc: systemic sclerosis; IPF: idiopathic pulmonary fibrosis; COPD: chronic obstructive pulmonary disease; FVC: forced vital capacity; FEV1: forced expiratory volume in $1 \mathrm{~s} ;{ }^{*}$ :time of diagnosis and onset of symptoms were not evaluated in patients with COPD: ${ }^{* *}$ : all patients were former smokers, having stopped for at least one year; ${ }^{* *}$ : data evaluated in 30 patients with SSc as two failed to perform the respiratory function test for technical reasons; ${ }^{* * * *}$ : three patients with IPF made regular use of oxygen and were tested with the usual supplement. Differences in age, FVC and FEV1 between groups were analysed using ANOVA. The time of diagnosis and onset of symptoms among patients with SSC and IPF was analysed using an unpaired t-test. 


\section{Original article}

\section{The 6MWT in interstitial lung disease}

Initially, we compared the parameters of the $6 \mathrm{MWT}$ between the groups with ILD (SSc and IPF) and observed no statistically significant differences in heart rate and respiratory rate data measured before, immediately after and at the end of the test. The same happened when we checked blood $\mathrm{SaO}_{2}$ measured immediately after the test, i.e. no significant differences were found between the values achieved by patients with IPF or SSc (Table 2).

Although there was a statistically significant difference in the mean $\mathrm{SaO}_{2}$ measured before the test in both groups ( $\mathrm{SSc}=96.30 \pm 0.4917 \%$, IPF $=95.00$ $\pm 0.3810 \% ; p=0.0412$ ), all patients were within the normal range.

In the 6MWT, patients with SSc walked a longer distance compared to patients with IPF when we consider the absolute values in meters (SSc $=434.3 \pm$ $14.77 \mathrm{~m}, \mathrm{IPF}=374.8 \pm 21.79 \mathrm{~m} ; \mathrm{p}=0.0279$ ). However, the SSc group was younger than the IPF one. To correct for this difference, the percentage of the predicted distance was calculated using Enright and Sherrill's equation. ${ }^{15}$ Comparing the percentage obtained by the two groups, we found no statistically significant difference (SSC = $111.5 \pm 4.41 \%, \mathrm{IPF}=115.5 \pm 6.24 \% ; \mathrm{p}=0.5908$ ).

Thus, patients with SSc and IPF had similar behavior with respect to the 6MWT data. These patients were grouped and compared to a group of COPD patients.

6MWT performed in interstitial lung disease and COPD patients

When comparing the data obtained in the 6MWT for ILD (SSc and IPF) patients with those with COPD, statistical differences began to emerge, especially in relation to the distance walked and arterial $\mathrm{SaO}_{2}$. Patients with ILD walked on average $113.5 \pm 3.72 \%$ of the distance predicted, while COPD patients reached $84.36 \pm 4.81 \%$ ( $\mathrm{p}<0.0001)$. In absolute values, ILD patients walked on average $52 \mathrm{~m}$ more than patients with COPD. Despite this better performance in relation to the distance, patients with ILD had a

Table 2. Data measured during the 6-minute walk test in patients with interstitial lung disease

\begin{tabular}{|c|c|c|c|}
\hline & $\begin{array}{c}\text { SSc } \\
(n=32)\end{array}$ & $\begin{array}{c}\text { IPF } \\
(n=32)\end{array}$ & $p$-value \\
\hline HR pre & $79.47 \pm 1.95$ & $82.38 \pm 2.71$ & 0.388 \\
\hline HR post & $103.3 \pm 3.02$ & $108.4 \pm 4.19$ & 0.328 \\
\hline HR pre-post & $23.81 \pm 2.70$ & $26.0 \pm 2.63$ & 0.564 \\
\hline RR pre & $22.22 \pm 0.95$ & $27.0 \pm 1.87$ & 0.075 \\
\hline RR post & $31.50 \pm 1.34$ & $36.44 \pm 2.54$ & 0.091 \\
\hline RR pre-post & $8.65 \pm 0.87$ & $9.40 \pm 1.36$ & 0.643 \\
\hline Borg dyspnoea pre & $0.50 \pm 0.22$ & $1.07 \pm 0.26$ & 0.102 \\
\hline Borg dyspnoea post & $2.18 \pm 0.49$ & $2.98 \pm 0.46$ & 0.267 \\
\hline Borg fatigue pre & $0.68 \pm 0.26$ & $0.90 \pm 0.25$ & 0.544 \\
\hline Borg fatigue post & $2.17 \pm 0.44$ & $2.19 \pm 0.42$ & 0.979 \\
\hline $\mathrm{SaO}_{2}$ post* & $86.69 \pm 1.85$ & $84.13 \pm 1.65$ & 0.304 \\
\hline$\Delta \mathrm{SaO}_{2}$ pre to post* & $9.65 \pm 1.64$ & $10.88 \pm 1.49$ & 0.583 \\
\hline
\end{tabular}

Legend: SSc: systemic sclerosis; IPF: idiopathic pulmonary fibrosis; 6MWT: 6-minute walk test; HR: heart rate; HR pre: HR measured prior to the walk test; HR post: HR measured immediately after the test; HR pre-post: difference between the final and baseline HR values; RR: respiratory rate; RR pre: RR measured prior to the 6MWT; RR post: RR obtained immediately after the test; RR pre-post: difference between the final and baseline RR values; Borg: Modified Borg Scale of perceived dyspnoea; Borg pre: measured at baseline; Borg post: measured immediately after the $6 \mathrm{MWT} ; \mathrm{SaO}_{2}$ : arterial oxygen saturation; $\mathrm{SaO}_{2} \mathrm{pre} \mathrm{SaO}_{2}$ measured at baseline; $\mathrm{SaO}{ }_{2}$ post: $\mathrm{SaO}_{2}$ assessed immediately after completion of the test; $\Delta \mathrm{SaO}_{2}$ : difference of two saturation measurements; ( $\left.{ }^{*}\right)$ SaO ${ }_{2}$ could not be assessed in two patients before and in six at the end of the 6MWT in SSc patients due to Raynaud's phenomenon. 
greater decrease in $\mathrm{SaO}_{2}$ at the end of the test (ILD = $10.33 \pm 1.09 \%$, COPD $=4.60 \pm 0.37 \% ; \mathrm{p}<0.0001)$. The results for the distance walked in the test and blood $\mathrm{SaO}_{2}$ are shown in Table 3 .

\section{Discussion}

In our study, the data collected from the 6MWT performed by ILD patients (IPF and SSc) were very similar, suggesting that patients with interstitial lung fibrotic disease present similar patterns. When comparing patients with ILD and COPD, we realized that those with an obstructive pattern walked a shorter distance, with a statistically significant difference $(\mathrm{p}=0.0033)$.

Patients with ILD showed an increase in heart rate and respiratory rate after 6MWT, as expected. Evaluation of dyspnoea and fatigue measured by the Borg scale was also similar in both groups. The drop in blood $\mathrm{SaO}_{2}$ after the 6MWT was intense in some patients. Desaturation equal to or greater than four percentage points was observed in 26 of 30 patients with SSc and in 25 of 32 with IPF. Despite the presence of Raynaud's phenomenon in all SSc patients, it was possible to determine arterial $\mathrm{SaO}_{2}$ at baseline and at the end of the 6MWT in more than $90 \%$ of them.

Other studies have correlated a decline in walking distance with mortality and hospitalization due to exacerbations of the disease (Alahmari et al., 2016; Spruit et al., 2012). For some authors, the desaturation of patients with COPD during the 6MWT reveals a worse prognosis when compared to those patients who do not present a fall in blood oxygen saturation $\left(\mathrm{SaO}_{2}\right)^{16,17}$

Although studies on the effect of exercise in patients with ILD can be easily found, we found no consensus among authors. An article published by Godfrey, Bluestone and Higgs in 1969 demonstrated the concern of the authors in relation to the analysis of desaturation occurring in SSc patients during exercise. ${ }^{18}$ In a more recent study, Park et al. described hypoxaemia induced by exercise as a characteristic of interstitial lung disease (ILD) and suggested that, although some patients are not hypoxaemic at rest, $\mathrm{SaO}_{2}$ tends to drop abruptly early in the walk and that recovery is usually slow. ${ }^{19}$ Other authors sought to correlate the distance walked in the $6 \mathrm{MWT}$ by patients with restrictive diseases with data from the respiratory function test, with the Borg dyspnoea index and the health-related quality of life (HRQL) questionnaire. ${ }^{20-23}$ Others found no specificity or relevance in using the $6 \mathrm{MWT}$ in patients with SSc and pointed out that the distance walked by IPF patients is not a reliable indicator of mortality in these patients. ${ }^{24-26}$

Regarding the distance walked during the 6MWT, both SSc and IPF patients exceeded the expected theoretical values, according to Enright \& Sherrill's equation (1998). ${ }^{15}$ Since the ATS guideline recommends a 30-metre corridor instead of the 40-metre-long one we used, it is possible that this facilitated the walk and that patients may have obtained a better performance due to this choice. The distance walked by ILD patients does not correlate with the symptoms they presented,

Table 3. Comparison of arterial oxygen saturation and distance covered in the 6-minute walk test in patients with chronic obstructive pulmonary disease and interstitial lung disease

\begin{tabular}{lccc}
\hline & $\begin{array}{c}\text { COPD } \\
\mathrm{n}=50\end{array}$ & ILD & p-value \\
\hline SaO2 pre 6MWT* & $92.96 \pm 0.38$ & $95.63 \pm 0.31$ & $<0.0001$ \\
\hline SaO2 post 6MWT** & $88.36 \pm 0.35$ & $85.28 \pm 1.23$ & 0.0190 \\
$\Delta$ SaO2 pre-post 6MWT** & $4.60 \pm 0.37$ & $10.33 \pm 1.09$ & $<0.0001$ \\
D6MWT (m) & $352.4 \pm 10.80$ & $404.6 \pm 1.09$ & 0.0033 \\
D6MWT (\% predicted) & $84.36 \pm 4.81$ & $113.5 \pm 3.72$ & $<0.0001$ \\
\hline
\end{tabular}

Legend: $\mathrm{COPD}$ : chronic obstructive pulmonary disease; $\mathrm{SaO}_{2}$ : arterial oxygen saturation; $\mathrm{SaO}_{2}$ pre: $\mathrm{SaO}_{2}$ measured before the test; $\mathrm{SaO}_{2}$ post: $\mathrm{SaO}_{2}$ assessed immediately after completion of the test; $\Delta \mathrm{SaO}_{2}$ : difference of two $\mathrm{SaO}_{2}$ measurements; D6MWT: distance covered in the 6-minute walk test; *: amounts relate to 62 patients with interstitial disease, because it was not possible to assess the initial $\mathrm{SaO} 2$ in two patients due to Raynaud's phenomenon; **: amounts relate to 58 patients with interstitial disease, because it was not possible to assess the $\mathrm{SaO}_{2}$ immediately after the test in six patients due to Raynaud's phenomenon. 
suggesting that this equation may not be appropriate in the case of ILD. Alternatively, we can postulate that the distance achieved during the 6MWT is not related to the prognosis of patients with SSc and IPF. However, as this study did not predict the longitudinal observation of these patients, we cannot reach such a conclusion.

Both FVC and $\mathrm{FEV}_{1}$ were reduced in both groups of patients with ILD, as expected, since these are diseases with a restrictive pattern, characterized by reduced volume and lung compliance. ${ }^{6}$ The $\mathrm{FEV}_{1} / \mathrm{FVC}$ ratio observed was normal. Despite a history of smoking in nine SSc and 24 IPF patients, only one patient with SSc presented an $\mathrm{FEV}_{1} / \mathrm{FVC}$ ratio below 70\%. Interestingly, we note that the IPF group showed significantly higher $\mathrm{FEV}_{1} / \mathrm{FVC}$ ratio values, suggesting the presence of above-normal flows and consequently greater impairment of lung elasticity.

SSc and IPF are different diseases, presenting distinct clinical and functional patterns. In our study, SSc patients were younger, more commonly female and had a longer course of disease when compared with IPF patients, who were older, presented more pulmonary fibrosis in the CT scan and were more likely to be using continuous oxygen therapy. Even with the important differences observed in both groups, no parameter obtained in the 6MWT was able to indicate such peculiarities. More interesting still was the fact that they walked long distances, further than expected.

As no differences were found in the ILD group, we decided to compare it with obstructive disease to see if, in this case, the 6MWT could perceive differences between patients with restrictive and obstructive disease. For this analysis, all patients with SSc and IPF were grouped, totaling 64 ILD patients, and were compared with a group of 50 patients with COPD.

When comparing patients with ILD and COPD, we realized that those with an obstructive pattern walked a shorter distance, with a statistically significant difference $(p=0.0033)$. The COPD group did not reach the normal theoretical value, showing correlation with clinical symptoms. These data are consistent with those found in the literature. Rasekaba et al. described COPD patients who walked less than $350 \mathrm{~m}$ during the $6 \mathrm{MWT}$ as presenting increased mortality. The same authors suggested that desaturation during the test could be an important prognostic indicator in patients with ILD. ${ }^{27}$

In our study, both ILD and COPD patients presented desaturation during the test; however, the ILD group showed a much more significant fall. Patients with SSc and IPF walked further and also desaturated more than the COPD group. In a study that analyzed 110 patients with SSc, Villalba et al. reported a significant correlation between oxygen desaturation $(\geq 4 \%)$ and four variables: age, dyspnoea index, reduced FVC (<80\%) and the presence of anti-Scl-70 antibody. ${ }^{28}$ In IPF, other studies highlighted that the degree of desaturation could be related to high risk of mortality and that the distance walked might be a good follow-up biomarker, but not a reliable variable related to mortality. ${ }^{24-26}$ The aim of this study was not to correlate the 6MWT with mortality, but one should note that, among our IPF patients, several had severe respiratory symptoms and three were using supplementary oxygen. Still, these patients performed well during the 6MWT.

The results of this study suggest that the parameters obtained in the 6MWT should be analyzed taking into account the diagnosis of pulmonary disease. ILD patients (SSc and IPF) did not differ in relation to the 6MWT, presenting significant oxygen desaturation at the end of the test and walking long distances, achieving more than $100 \%$ of the expected for age, weight and height. The decrease of saturation appears to be the main data extracted from the 6MWT in ILD. Importantly, we only evaluated patients with SSc and IPF and these results should not be generalized to other restrictive diseases. COPD patients walked shorter distances and did not reach the predicted percentage. They also had lower oxygen desaturation values than those found in SSc and IPF. Thus, we suggest that the main parameter to be evaluated in ILD is the drop in saturation during the 6MWT and not the distance, as should be the case in relation to COPD.

We emphasize the need for further studies involving other ILD in order to observe the different behavior of each of them during exercise and to assess whether they can be considered as a single entity related to the $6 \mathrm{MWT}$.

\section{Conclusions}

The data suggest that 6MWT should be analyzed according to the diagnosis of the patient and that, differently from COPD patients, the main parameter to be evaluated in the ILD group could be the drop in saturation and not the distance walked.

\section{Conflict of interest statement}

The authors declare that there is no conflict of interest related to this manuscript. 


\section{Authors contribution statement}

All authors participated in the manuscript and approved the final version.

\section{Referências}

1. Denton CP. Advances in pathogenesis and treatment of sys. temic sclerosis. Clin Med. 2016;16(1):55-60

2. Cappelli S, Bellando Randone S, Camiciottoli G, et al, Interstitial lung disease in systemic sclerosis: where do we stand? Eur Respir Rev. 2015 Sep:24(137):411-9

3. Rubio-Rivas M, Royo C, Simeón CP, Corbella X, et al. Mortality and survival in systemic sclerosis: systematic review and meta-analysis. Semin Arthritis Rheum. 2014 Oct;44(2):208-19

4. Sgalla G, Biffi A, Richeldi L. Idiopathic pulmonary fibrosis: Diagnosis, epidemiology and natural history. Respirology. 2016 Apr:21(3):427-37

5. Baddini-Martinez J, Baldi BG, Costa CH da, et al. Update on diagnosis and treatment of idiopathic pulmonary fibrosis. J Bras Pneumol. 2015 Sep;41(5):454-66.

6. Crisafulli E, Torres A. COPD 2017: A Year in Review. COPD: Journal of Chronic Obstructive Pulmonary Disease. 2018;1-5.

7. Celli BR, MacNee W, Agusti A, et al. Standards for the diagnosis and treatment of patients with COPD: a summary of the ATS/ERS position paper. Eur Respir J. 2004:23(6):932-46.

8. da Costa $\mathrm{CH}$, da Silva KM, Maiworm A, et al. Can we use the 6-minute step test instead of the 6-minute walking test? An observational study. Physiotherapy. 2017;103(1):48-52.

9. Rostagno C. 6MWT Predicts Survival Better Than CPET in Patients with Stable Cardiomyopathy. Br J Med Med Res. 2012:2(3):386-95.

10. van den Hoogen F, Khanna D, Fransen J, et al. 2013 classification criteria for systemic sclerosis: an American College of Rheumatology/European League against Rheumatism collabo rative initiative. Arthritis Rheum. 2013 Nov:65(11):2737-47.

11. Raghu G, Collard HR, Egan JJ, et al. An official ATS/ERS/JRS/ ALAT statement: idiopathic pulmonary fibrosis: evidence-based guidelines for diagnosis and management. Am J Respir Crit Care Med. 2011 Mar 15;183(6):788-824.

12. 'Global Strategy for the Diagnosis, Management, and Prevention of Chronic Obstructive Lung Disease 2017 Report: GOLD Executive Summary.' Vogelmeier CF, Criner GJ, Martinez FJ, et al. Eur Respir J 2017; 49: 1700214. Eur Respir J. 2017;49(6):1750214

13. ATS Committee on Proficiency Standards for Clinical Pulmonary Function Laboratories. ATS statement: guidelines for the six-minute walk test. Am J Respir Crit Care Med. 2002 Jul. $1 ; 166(1): 111-7$
14. The Borg Rating of Perceived Exertion (RPE) Scale. In: Care of the Obese in Advanced Practice Nursing.

15. Enright PL, Sherrill DL. Reference Equations for the Six-Min ute Walk in Healthy Adults. Am J Respir Crit Care Med. 1998; 158(5):1384-7.

16. Crisafulli E, lattoni A, Venturelli $E$, et al. Predicting Walking-Induced Oxygen Desaturations in COPD Patients: A Statistical Model. Respir Care. 2013;58(9):1495-503

17. Waatevik M, Johannessen A, Real FG, et al. Oxygen desatura tion in 6-min walk test is a risk factor for adverse outcomes in COPD. Eur Respir J. 2016:48(1):82-91.

18. Godfrey S, Bluestone R, Higgs BE. Lung function and the response to exercise in systemic sclerosis. Thorax $1969: 24(4): 427-34$

19. Park JH, Jegal Y, Shim TS, et al. Hypoxemia and arrhythmia during daily activities and six-minute walk test in fibrotic interstitial lung diseases. J Korean Med Sci. 2011 Mar;26(3):372-8.

20. Buch $M H$, Denton CP, Furst DE, et al. Submaximal exercise testing in the assessment of interstitial lung disease secondary to systemic sclerosis: reproducibility and correlations of the 6-min wall test. Ann Rheum Dis. 2007 Feb;66(2):169-73.

21. Lederer DJ, Arcasoy SM, Wilt JS, et al. Six-minute-walk distance predicts waiting list survival in idiopathic pulmonary fibrosis. Am J Respir Crit Care Med. 2006 Sep 15;174(6):659-64.

22. Manali ED, Lyberopoulos P, Triantafillidou C, et al. MRC chronic Dyspnea Scale: Relationships with cardiopulmonary exercise testing and 6-minute walk test in idiopathic pulmonary fibrosis patients: a prospective study. BMC Pulm Med. 2010 May $28: 10: 32$

23. Verma G, Marras T, Chowdhury N, et al. Health-related quality of life and 6 min walk distance in patients with idiopathic pulmonary fibrosis. Can Respir J. 2011 Sep; 18(5):283-7.

24. Schoindre Y, Meune C, Dinh-Xuan AT, et al. Lack of specificity of the 6-minute walk test as an outcome measure for patients with systemic sclerosis. J Rheumatol. 2009 Jul;36(7):1481-5.

25. Caminati A, Bianchi A, Cassandro R, et al. Walking distance on 6-MWT is a prognostic factor in idiopathic pulmonary fibrosis. Respir Med. 2009 Jan; 103(1):117-23

26. Flaherty KR, Andrei A-C, Murray S, et al. Idiopathic pulmonary fibrosis: prognostic value of changes in physiology and six-minute-walk test. Am J Respir Crit Care Med. 2006 Oct $1 ; 174(7): 803-9$

27. Rasekaba T, Lee AL, Naughton MT, et al. The six-minute walk test: a useful metric for the cardiopulmonary patient. Intern Med J. 2009 Aug; 39(8):495-501.

28. Villalba WO, Sampaio-Barros PD, Pereira MC, et al. Six-minute walk test for the evaluation of pulmonary disease severity in scleroderma patients. Chest. 2007 Jan;131(1):217-22. 